\title{
Left atrial appendage tear due to blunt chest trauma: off-pump repair
}

\author{
Kaptaniderya Tayfur ${ }^{1}$, Mihriban Yalcin ${ }^{1}$, Serkan Yazman ${ }^{1}$, Mehmet Senel Bademci ${ }^{1}$, Sezgin Albayrak² \\ ${ }^{1}$ Department of Cardiovascular Surgery, Ordu State Hospital, Ordu, Turkey \\ ${ }^{2}$ Department of Cardiology, Ordu State Hospital, Ordu, Turkey
}

\begin{abstract}
Left atrial appendage tear due to blunt trauma is a very rare clinical entity with high mortality rates. Traumatized patients may have no symptoms, or be in a cardiogenic shock state. For diagnosis, it is crucial to determine hemopericardium by echocardiography. Herein, we report a 28 -year-old male patient who developed left atrial appendage tear following a fall from a higher distance. He underwent successful off-pump repair of the tear through a median sternotomy.
\end{abstract}

Eur Res J 2016;2(3):225-227

Keywords: Left atrial appendage tear; blunt chest trauma; off-pump; surgery

\section{Introduction}

Cardiac rupture dependent on blunt trauma is related to high mortality. The incidence varies between $0.16 \%$ and $2 \%$, and is considerably rare [1]. A significant number of the patients are lost, due to late initial intervention, insufficiency at transportation, and delay of operation. In this case presentation, a patient who developed left atrial appendage rupture after falling from a high distance was reported.

\section{Case Presentation}

A 28-year-old male patient was taken to the emergency room because of falling from a walnut tree with a height of approximately 6 meters. He was conscious, oriented, and cooperated. His complaint was dyspnea. At the physical examination, he had no major finding, except scratches on the left part of his face. His respiratory rate was 24 breaths per minute, blood pressure was $70 / 50 \mathrm{mmHg}$, and heart rate was 124 beats per minute. In his chest x-ray, enlargement of the cardiac silhouette was observed. His hemoglobin value was $9 \mathrm{~g} / \mathrm{dl}$, and hematocrit value was $27 \%$. Hemopericardium was observed at the thoracoabdominal computed tomography (Figure 1). Aorta and major vessels were intact. Echocardiograhy showed pericardial effusion, which was causing a pressure of approximately $2 \mathrm{~cm}$. The patient was taken to the operation room instantly without losing time, with placing a required vascular access for blood and volume transfusion.

Following median sternotomy, the pericardium 
was explored and approximately $1400 \mathrm{cc}$ fresh blood was aspirated; though, active bleeding still existed. No bleeding focus was observed at aorta, right atrium, right ventricle and caval veins, and the surface of the back of the heart was checked. A rupture and active bleeding was detected at the right side of the left atrial appendix (Figure 2).

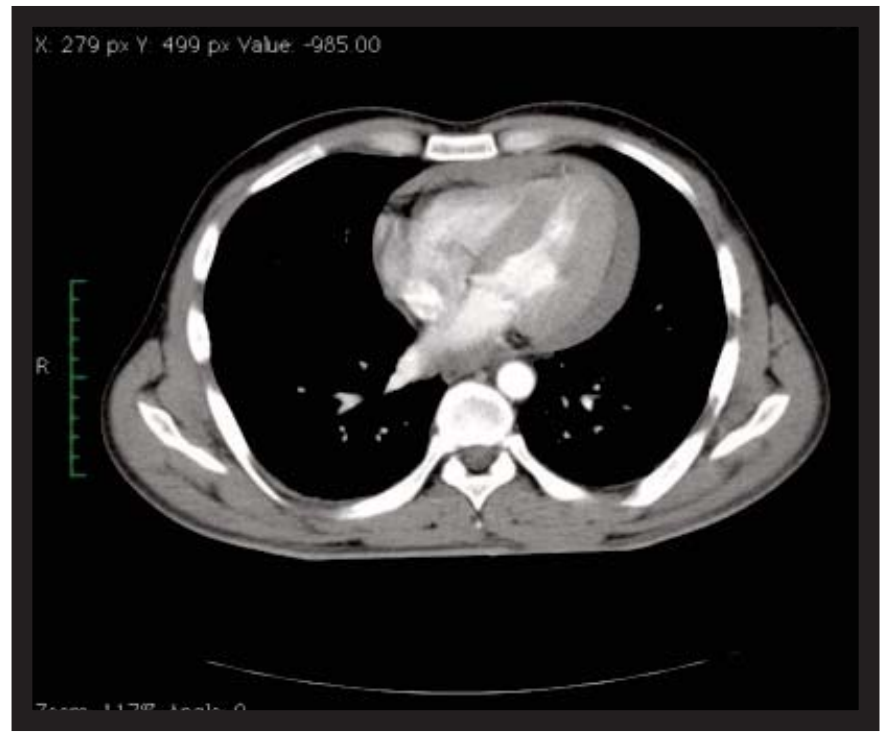

Figure 1. Thoracoabdominal computed tomography shows hemopericardium

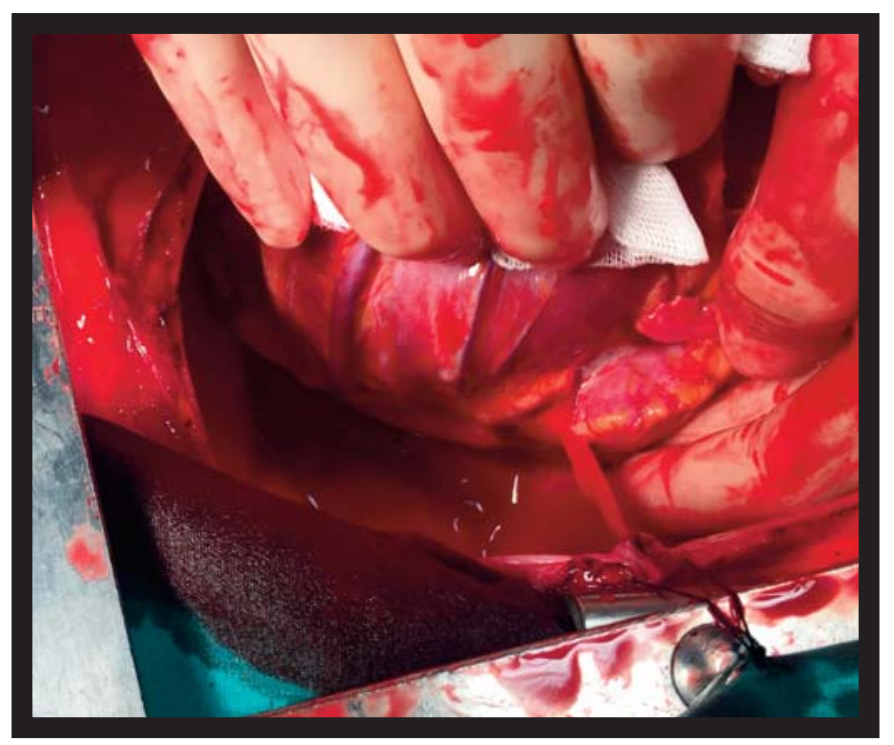

Figure 2. Intraoperative view of the left atrial appendage tear

The defect was repaired with pledgeted 4-0 polypropylene sutures using off-pump approach (on a beating heart), and the bleeding was stopped (Figure $3)$. The sternum was closed after the last controls, when we were sure that there was no bleeding, and the patient was taken to the intensive care. The patient who had no problem at the postoperative period was discharged at the $4^{\text {th }}$ day.

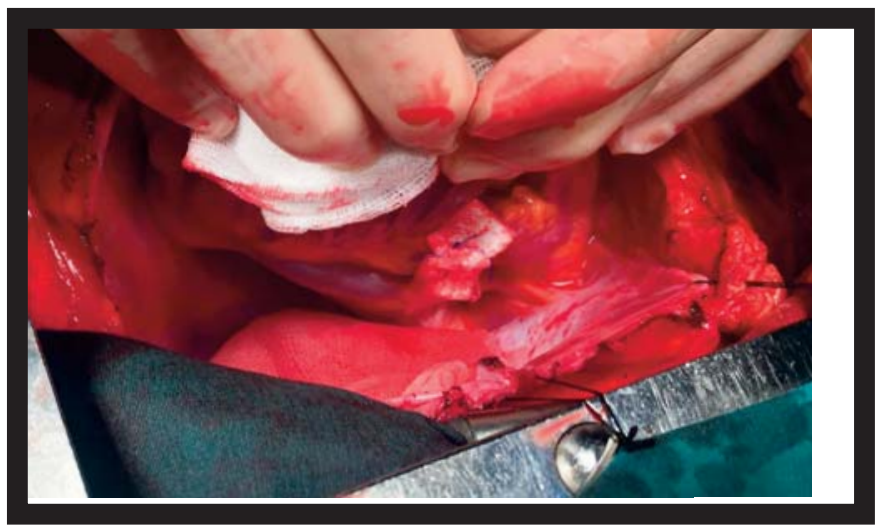

Figure 3. The view of the tear repaired with pledgeted sutures

\section{Discussion}

Approximately $25 \%$ of deaths occur due to a chest injury caused by blunt trauma. Cardiac injuries due to blunt chest trauma can cause hemothorax and tamponade and are at high risk of mortality. Blunt chest trauma can be traced from a simple rib fracture to cardiovascular rupture [2]. The incidence of injury of heart and major vessels with blunt chest traumas varies between $4 \%$ and $1 \% 5$ [3]. Cardiac rupture is a rare complication which occurs in 1 of 2400 blunt truma patients [4]. In 160 autopsies in trauma, where the cause is blunt mechanisms, cardiac rupture was found in $96.9 \%$ [5].

The rapid deceleration with disruption of the atria from their connections to the vena cava and pulmonary veins is the most popular theory of cardiac rupture following blunt thoracic trauma [6]. The chamber tear is related to a high rate of mortality. Because of the low-pressure chamber, unlike ventricle ruptures, immediate death is delayed in atrial rupture [7]. National trauma data bank reports that the chamber tears make the $0.041 \%$ of all trauma cases and there is a mortality rate of $89.2 \%$ [4].

Due to the anatomical localization of cardiac injuries, the most affected chamber is right ventricle, and than left ventricle is the second one [8]. Brathwaite et al. [9] reported that left atrial injury occurs in the $25 \%$ of the cases with cardiac rupture, and atrial appendage and pulmonary vein-atrial junction are the most affected sides. In a study that reported the anatomical distribution of 42 injuries; the number of patients have affected chambers are; 21 patients $(50 \%)$ in right atrium, 7 patients $(17 \%)$ in right ventricle, 10 patients (24\%) in left atrium, and 4 patients in left ventricle [10]. Tanoue et al. [11] reported a case that they operated because of the 
rupture of left atrial appendage due to the blunt trauma. Akar et al. [12] reported the case of a 33-yearold man with a rupture of the left atrium after blunt thoracic trauma.

It is usually difficult to diagnose cardiac tear in falling from high levels which doesn't have a clinical sign. The clinical signs may vary from no symptoms to cardiogenic shock. In the early stage typical symptoms of tamponade (hypotension, elevation of central venous pressure, decreased heart sounds and tachycardia) are not available in all patients, so if the patients have minimal thoracic injury and vitable signs, the results of injury may be overlooked. In cardiac injuries, the hemopericardium that is shown with echocardiograhy at emergency room is very important and helpful for the diagnosis. In our patient, the prominent pericardial effusion showed by echocardiograhy was also helpful in the detection of the cardiac injury.

The required fluid replacement and urgent surgery should be performed to patients at the time of diagnosis. The tamponade should be relieved quickly in heart injuries. In our case as well, the blood pressure increased to $130 / 70 \mathrm{mmHg}$ from $80 / 50 \mathrm{mmHg}$, following the drainage of blood after the pericardium was opened, resulting from the heart's contractions turning into normal state and the cardiac functions were normalized.

In these cases, there is no consensus on approaching with median sternotomy or thoracotomy. As the median sternotomy provides advantage for cardiopulmonary bypass when needed, by exploring the whole heart and the aorta and because we didn't know the type of the injury we would have faced with, we chose median sternotomy in this case. In addition, because a considerable amount of active bleeding was continuing, we didn't want to lose time with cardiopulmonary bypass and we decided that we could repair the injury site by suturing; so we elevated the heart and performed an off-pump (on a beating heart) repair.

\section{Conclusion}

As a result, cardiac rupture, especially the left atrial appendage tear due to blunt trauma is a condition that is a rare entity with a high rate of mortality. In these patients, it is life-saving to diagnose quickly and to repair the heart by off-pump or on-pump surgical approach.

\section{Informed consent}

Written informed consent was obtained from the patient for the publication of this case report.

\section{Conflict of interest}

The authors declared that there are no potential conflicts of interest with respect to the research, authorship, and/or publication of this article.

\section{References}

[1] Schultz JM, Trunkey DD. Blunt cardiac injury. Crit Care Clin 2004;20:57-70.

[2] Turk F, Ozcan V, Yuncu G, Ekinci Y, Girgin S. [An isolated right auricular rupture following blunt chest trauma causing massive hemothorax]. Turk Gogus Kalp Dama 2014;22:410-3. [Article in Turkish]

[3] Adalia R, Sabater L, Azqueta M, Muntanya X, Real MI, Riambau V, et al. Combined left ventricular aneurysm and thoracic aortic pseudoaneurysm caused by blunt chest trauma. J Thorac Cardiovasc Surg 1999;117:1219-21.

[4] Teixeira PG, Inaba K, Oncel D, DuBose J, Chan L, Rhee P, et al. Blunt cardiac rupture: a 5-year NTDB analysis. J Trauma 2009; 67:788-91.

[5] Fedakar R, Turkmen N, Durak D, Gundogmus UN. Fatal traumatic heart wounds: review of 160 autopsy cases. Isr Med Assoc J 2005;7:498-501.

[6] Nan YY, Lu MS, Liu KS, Huang YK, Tsai FC, Chu JJ, et al. Blunt traumatic cardiac rupture: therapeutic options and outcomes. Injury 2009;40:938-45.

[7] Alameddine AK, Alimov VK, Alvarez C, Rousou JA. Unexpected traumatic rupture of left atrium mimicking aortic rupture. J Emerg Trauma Shock 2014;7:310-2.

[8] Ata Y, Turk T, Yalcin M, Selimoglu O, Ozyazicioglu A, Yavuz S. [Heart Injuries]. IU Kardiyol Enst Derg 2009;8:16-9. [Article in Turkish]

[9] Braithwaite CE, Rodriguez A, Turney SZ, Dunham CM, Cowley R. Blunt traumatic cardiac rupture: a 5-year experience. Ann Surg 1990; 212:701-4.

[10] Ryu DW, Lee SY, Lee MK. Rupture of the left atrial roof due to blunt trauma. Interact Cardiovasc Thorac Surg 2013;17:912-3.

[11] Tanoue K, Sata N, Moriyama Y, Miyahara K. Rupture of the left atrial 'basal' appendage due to blunt trauma in an elderly patient. Eur J Cardiothorac Surg 2008;34:1118-9.

[12] Akar I, Ince I, Aslan C, Ceber M, Kaya I. Left atrial rupture due to blunt thoracic trauma. Ulus Travma Acil Cerrahi Derg 2015;21:303-5. 